\title{
An Elite Sporting Organization's Perceptions to the Uptake of Information Technology
}

\author{
Rene Leveaux \\ University of Technology, Sydney, Australia \\ rene.leveaux@uts.edu.au
}

Received date: 29 March 2016; Accepted date: 13 December 2016; Published date: 11 July 2017

Academic Editor: Tengku Adil Tengku Izhar

Copyright @ 2017. Rene Leveaux . Distributed under Creative Commons CC-BY 4.0

\begin{abstract}
In recent years, technology has enabled sporting organizations to become innovators in the global sports arena. Elite sporting teams and bodies are becoming increasingly dependent on technology for daily operations and subsequently these organizations are more and more reliant on technological developments in sport. Player training and management technologies and team performance tools have given sporting organizations the avenues to become more competitive. Organizations invest in information technology for many reasons, for example cutting costs, increase in production and services without increasing costs, improving the quality of services or products and sporting organizations and bodies are no different in looking to technology to gain competitive edges as well as improvement of athlete preparation. However, in spite of these innovations and the potential to gain competitive edges, some seem to struggle with technology resulting in ambiguous and sometimes negative perceptions of IT services. Through a qualitative case study and using interviews with a short survey, the building of credibility in sporting organizations through education and the development of positive perceptions of information technology was examined. The findings provide a basis for further studies and possible trials of differing education formats in technology to further develop both the positive acceptance of sports related technologies and assist in improving the sporting organization's environment.
\end{abstract}

Keywords: Credibility, Information Technology, Sport

\section{Introduction}

Elite sporting organizations and clubs, as well as business organizations operate in a strategic information technology (IT) environment, where the alignment of business and information strategies should be a significant focus for organisational effort. In organisations poor relationships between other business units and IT directly influences where the relationship between the IT function and the rest of the business is poor, this severely influences their ability to make the sort of contribution that the business demands. IT planning is crucial to the alignment of the IT function and business objectives (Reich and Berbast 2013). 
Over the past 50 years, the use of information technology is possibly one of the most significant developments in the commercial world (Doherty 2014) and this similarly applies to the world of sport. Literature has many examples of organizations, including sporting organizations, who have obtained competitive advantage from the introduction and uses of IT. However, IT can provide a wide range of benefits to an organization (Nguyen et al 2015) however in sport the IT resources have been managed by staff in an environment where the potential for loss of knowledge is high due to staff turnover which may occur over short periods due to competition structures, typically season to season, differing from the business sector.

The benefits of modern technologies are only meaningful when they are readily accepted and can be easily applied and used by end user (Doherty 2014), and as such if the new technologies are not willingly accepted and used, will not bring the full benefits to the organization. User may not perceiving IT as a benefit or not may not necessarily depend on the technical quality of the systems provided to users. Thus, it is important to find out why users may have a negative manner perception of IT.

This exploratory paper reports on an attempt to improve the user perception of the use of IT in an Australian sporting organization which has struggled to improve internal user satisfaction. Based on a snapshot of internal user satisfaction survey results and interviews, the paper presents a proposed method to enhance satisfaction and improve the users' perception of IT.

IT in the Organization

The IT function of a sporting organization is in somewhat of a quandary as to where it actually resides. Researchers over the last 30 years have put forward the idea of IT being a strategic asset and it being used strategically to further the organization's goals. There is the perspective that to be competitive the organization would not survive without it. This additionally applies to elite sporting organizations and clubs.

IT is the backbone for most people's daily lives (Abdillah 2014) which has in turn converted business processes and practices, and changed the way business is conducted (Maklan et al 2015) and in some instances organization survival has been directly attributed to the use of IT (Paroutis et al 2014). Previously, IT had been seen as primarily an operational support function in many organizations (Beheshti 2004) with little emphasis placed on its importance to the organizations.

Though it may not be possible to quantify completely the value of the role of IT to a business or sporting organization, it seems imperative that appropriate investments continue to be made in IT to maintain competitiveness. The earlier perceptions of the "role of IT function in an organization" directly impacting the effectiveness of the development of IT capabilities (Ramakrishna and Lin, 1999) still continues. Avison et al. (1999) indicated that while IT can be critical to the organization's ability to conduct and develop business, the organizational role of IT is often considered as a secondary activity. A by-product of this is that organizations may be reluctant to divert appropriate investment towards enhancing the IT function, and in sporting organizations and clubs this is often the one area where investment is not seen with the same importance as in the corporate environment.

IT usage is arguably one of the most significant phenomena to occur within sport in past two (2) decades. It may be used for general organizational functions including operational and managerial control, strategic planning and decisionmaking. However, in the sporting arena the applications of IT have increasingly extended to various functions surrounding the preparation of the individual athlete and/or team. 


\section{Perception}

Perception is based on the understanding one has of something or someone. It is an impression that a person has based on their understanding of another entity (be that a physical thing, a group such as a team or an organization or another person). Hence perception can be defined as "the process of making sense out of one's environment" (Daft 1997: p562) or "the process of selection, organization, and interpretation of stimuli from the environment" (Milton et al, 1984: p22).

When looking at perception in a sporting organization or club, the impressions that a coach/athlete/support staff member has are no doubt influenced by their past experiences, as in any organization (Milton et al. 1984). As they acquire new information or their environment changes, no doubt their perceptions will also shift.

\section{Negative Perception of IT}

Negative perceptions of IT are often caused by the misunderstandings and lack of awareness of the technology (Overby, 2005a). Today an IT outage can severely impact a company's ability to manufacture and deliver its goods and services, impact customer relationships and reputation, yet only a few companies have thoroughly identified and lessened their exposure to this risk (Štok et al, 2010).

Sun (2010) argues that organizations must have a learning culture and as a result attention must be paid to the training of people as well as selection of personnel. This is an important concept for organizations and the negative perception of IT within the organizations. It appears to be human nature to act on perceptions, even though it may not be valid, and as such it being negatively viewed can have disastrous consequences within an organization.

In any organization it is hard to change negative perceptions once they are instilled. Even by delivering projects successfully and ensuring IT deliverables, such as network uptime, are maintained at optimum service levels, changing the mindset of end users within the organization may take considerable effort. Overby (2005a) believes it is impossible to improve how IT is perceived unless basic competence and implementation success has been achieved. Simply being competent or achieving a major project win is not enough to change a poor perception.

Some consequences of a negative perception of IT within a sporting organization include missed opportunities to apply relevant technologies to enable growth and innovation, ineffective IT operations for innovation and growth, inefficient IT operations, IT budget cuts, turnovers in coaching staff / support staff / player morale, and user resistance to IT systems.

\section{Credibility and Trust}

A common misconception is that both credibility and trust are often thought to be the same, but this is not the case as one party could have someone's trust but they may not be credible to others. Trust on the other hand requires one party to knowingly place themselves in a position where they may be at risk from or be vulnerable to another party and can be a strong mediator for relationships. (Park et al 2012). Credibility and trust are two important elements that all should be strived for the success of the use of IT in any organization, including sporting organizations / clubs.

Credibility is multi-dimensional and complex and Rieh (2014) notes credibility has been defined to include such relationship concepts as believability, currency, fairness, accuracy, trustworthiness, completeness, reliability, and objectivity. In many situations people find others with similar thoughts and beliefs to be more credible than those with different thoughts and beliefs. Lacking the understanding of an organization's IT infrastructure leads to the formation of negative perceptions and poor credibility. As with industry, in a sporting organization it is important to determine the level of credibility, and if low credibility exists, how this can be addressed and what can be 
done to improve the credibility and as such change negative perceptions of IT.

A common theme to build credibility is to manage expectations and not over promise. The credibility an IT function has within the club's users (coaching staff, support staff and players) is additionally based on past working experiences and relationship commitments (Huang \& Qing 2007, Park et al 2012). Credibility can be easily damaged by a poor performance in the provided IT service. Once it has been lost, regaining credibility is difficult as restoring confidence may take considerable time and the IT function may continue to suffer for several years (Cormack et al 2001, Horn Nord et al 2007). To ensure confidence in IT is retained, regular updates of achievements through the application of the organization's IT performance should be communicated throughout the organization, along with communicating detailed information about the IT's attributes and benefits. (Lunney et al 2016).

Perceived usefulness is a key factor that effects attitude and use of IT. If the technology is deemed to be useful and by providing the users with detailed information regarding the product's attributes and benefits, this may favorably increase attitudes and in turn increase adoption and use of the technology. (Lunney et al 2016)

Trust also implies both parties will lower their own interests in order to achieve individual and joint goals once trust has been established through friendship, dedication, and a successful history of working together. Poor performance of IT may not necessarily damage trust, and Huang and Quing (2007) consider good performance will only reinforce the trust already gained and improve credibility. In a sporting club context, if a member of the coaching or support staff or a player is not trusted, they will not be credible, regardless of their expertise and performance, which, in turn may affect the credibility and acceptance of the IT system.

IT staff consult and communicate with all levels in the coaching staff and player group in order to build a common awareness and create a positive organization/club-wide impression of the IT function. By partnering with the various stakeholders in the team(s) to tackle problems with shared knowledge and information, IT staff can seek further opportunities to add value across the entire organization. When partnerships are based on trust, the joint effort will lead to enhanced outcomes as most people 'value someone they have confidence in and can trust' (Bhardwaj 2007: p57). By doing this the IT function will be more focused, credibility and trust between the IT and the club and team's stakeholders will be increased and all entities will form a sound partnership.

\section{Research Methodology}

This exploratory work reports on the attempts by a sporting organization to improve the perception and acceptance of IT within their community - a semiprofessional Australian sporting club competing in one of the premier level competitions in their country. The IT function has struggled over the years to gain meaningful acceptance and subsequently the uses and acceptances of IT dwindled rather than being further embraced.

Qualitative approach was used in this case study using a discussion group and interviews with a short survey. Using a qualitative approach provides the avenue to gain a greater understanding of the interviewee's experiences and personal views. All participants in the study participated voluntarily and were informed, if they wished to do so, they were able to withdraw from the study without the need to provide reason or justification.

The sporting organization was chosen due to the broad range of athletes competing at differing levels ranging from the social/weekend participant to individual full time athletes. The first grade / senior team had semi-professional and professional athletes on contract, of which some had additionally been recruited into the club.

The organization had various levels of successes and failures with the introduction of various information 
technologies ranging team and player management, match and player statistics to training and conditioning programs. The technologies used stand alone in so much that they are not formal requirements of the club or mandatory to compete in the competition. The introduction of technologies and their uses have been somewhat dependent on the relevant coaching staff of that season. There are some competition requirements where relevant match data and player statistical data are to be loaded to the competition management systems run externally by the competition management.

\section{Interviews}

A pre-interview discussion $(n=2)$ was held prior to the commencement of the preseason period in relation to the technologies in place at the club to provide the opportunity for other related topics to surface, as suggested by Patton (1990). A general interview script was developed based on issues derived from comments and points raised from the discussion. Interviews were used to provide the opportunity to draw on both the past and the present so as the extract a deeper understanding of issues compared to a simple survey type enquiry (McCracken, 1998). As indicated by Earlandson (1993), the use of semi-structured interviews provides the investigator the avenue to ask respondents for facts as well as gathering opinions. In all interviews the same format of questioning was employed $(n=11)$. All the participants were or had been involved in the club in either a coaching, team management or player roles for the previous season, and in the majority had been involved with the club for more than four years/seasons.

Chain sampling was used to solicit participants who are "information-rich" as Patton (1990) indicated are good examples and good interview subjects. All the 11 participants were chosen base on the individual's availability, experience with technology and technology being used in the club and in the sport.

This technique of purposeful sampling was employed due to the concerns in the study to maximize discovery of the problem and the heterogeneous patterns occurring with the framework of the study, which is supported by Erlandson (1993). The semistructured interviews were conducted at locations suitable to the interviewee and lasted approximately 20 to 25 minutes. Following the interview, the participant was asked to provide responses to a survey.

The interview questions focused on the views, if any, the participant had in relation to both the technology and the use of technology with the preparation of either the individual athlete or with the team. Views and / or opinions in related to any other sports, or technologies they may have been aware of being used in other sports were disregarded. Their personal viewpoints on information technology, in relation to the introduction of the technology and the levels of application, what they did or did not enjoy with the technology(s), and what aspects they appreciated or not were explored. Participants were also asked about they personally adapted to the IT, changes in their own practices and preparation leading up to, during and after a match were also explored. The interviews were recorded and transcribed for analysis. Clarification or further investigation was sought with follow-up phone calls to six respondents.

A case study is an investigation of a contemporary phenomenon within its reallife context providing rich contextual data obtained from an organizational setting, A single case study has the ability to increase our understanding of a particular situation (Yin 2003). It has been argued that a single case study, while not generalizable, has the ability to provide a valuable insight into a known context (Duhan et al 2001) and that the findings may be appropriate for someone in similar circumstances (Cousin and Jenkins 2001).

\section{The Field Site}

The organization being studied for the purpose of this study is a sporting organization with athletes competing at all levels from grassroots through to elite 
national players. The organization consists of athletes competing across five open age teams and three Under 21 age teams. Each team consists of fifteen players and a group of reserve athletes. The teams compete in a state's premier competition. On completion of the state competition, the state team champion competes against the premier team from the other leading state in Australia to determine the national champion.

The organizational structures of each club in this competition and the sport, although slightly different, are in essence very much the same. The structure of the club in this study has a head coach with each team having one or two team coaches and a team manager. A strength and conditioning team and medical and physiotherapy staff work across all teams and support the coaching staff. The organization has a structure with an operations manager overseeing the dayto-day running of the organization and reports to a board headed up by the organization's president. The IT staff are not directly linked to any specific team but provide IT support across all areas of the club. The overall team / player management is administered by the sporting organization's head coach.

\section{The Problem}

The organizational structure has a direct linkage to the problem as even though there is a head coach who oversees all teams and sets directions and processes for the season, individual coaches are not obligated to utilize the technologies. In some instances, due to individual preferences, some of the coaching introduce their own preferred information technologies, and only use a subset of the organization specific technologies or do not use the technologies at all. To some degree, the individual team staff work fairly autonomously.

The athletes, due to their own individual needs, either use their own technologies, data provided to them via the club's information technologies, or in the case of the fully contracted athletes, use technologies that they are required to use by the higher ranked organizations (e.g., state or national representative bodies). With some, it is a mix of all three.

When initiating a project requiring IT involvement, the head coach usually seeks an endorsement from the board and the technology is then introduced. It is then the responsibility of IT to implement and often manage the technology. There is very little consultation with either the other coaching staff, support staff or the IT staff.

There is very little education or hands on testing by the various end users. The coaching staff and athletes are provided with minimal information as to the functioning of the technology and the reasoning or requirement for the introduction of the specific technology(s). Individual teams, in the most, only utilize the components of the system that directly affect the athletes of their team or provided data only for their team by the head coach; and not of all athletes and teams in the organization. There is little knowledge within individual teams on how the other teams use the system. Once an information system has gone live, there is even lesser understanding within the club community of how the system holistically fits into the club's structures and processes.

This leads to frustration and eventually a negative perception of the system and IT in general. A single process within the club may involve multiple teams to complete the process. In not understanding the responsibilities of the other teams, users are open to unrealistic expectations of what the system has to offer, and in some cases what is expected. When given the opportunity, the individual teams often set expectations of the technology without regards for the needs of the remainder of the club. These then become unachievable and the blame is laid on the assumed inadequacy of the system, and eventually adds to this negative perception of IT.

As a typical input from various units within the club, for example, coaching staff and medical staff and strength and conditioning staff, some of these units do not appear to fully understand the impact their own unit has on the structure of the club's processes. 
Systems are built incorporating the needs of all teams / athletes, which is advantageous to IT staff as they are able to have a holistic understanding of the club's process. IT staff often appear to be more knowledgeable than individual units and users due to this holistic view of business processes.

\section{Interviews and Surveys}

Interviews were conducted during the preseason period (January / February) and followed by a survey. The survey was conducted again midway during the season proper. Interviews and the surveys were conducted at the completion of the season (September).
Figure 1 below is a summation of the three surveys. The survey taken in January/February was considered as baseline measurement to gauge and measure improvement. All team coaching staff considered a 5\% increase in satisfaction of the baseline to be an achievable target.

This comparison allows the perception of IT within the club and the results show the users hold a poor or negative perception. The survey questions included communication skills, professionalism, understanding of the technology, culture of IT in the club, ability to recommend solutions, quality and timeliness of delivery, value to the club and individual teams and athletes, and overall satisfaction.

\begin{tabular}{|c|c|c|c|c|c|c|}
\hline Team & Team A & Team B & Team C & Team D & Team E & Overall \\
\hline $\begin{array}{c}\text { Jan/Feb } \\
\text { (Baseline) }\end{array}$ & 6.4 & 7.1 & 6.0 & 6.8 & 6.5 & 6.56 \\
\hline $\begin{array}{c}\text { Target } \\
\text { (Baseline + } \\
\text { 5\%) }\end{array}$ & 6.72 & 7.45 & 6.3 & 7.14 & 6.83 & 6.88 \\
\hline $\begin{array}{c}\text { Mid-Season } \\
\text { May }\end{array}$ & 6.7 & 7.0 & 6.1 & 5.9 & 6.2 & 6.38 \\
\hline $\begin{array}{c}\text { End Season } \\
\text { September }\end{array}$ & 6.9 & 6.6 & 5.9 & 6.3 & 5.8 & 6.30 \\
\hline $\begin{array}{c}\text { Sept. vs. } \\
\text { Target } \\
\text { (Baseline } \\
+5 \%)\end{array}$ & $7.8 \%$ & $-5.7 \%$ & $-1.6 \%$ & $-7.3 \%$ & $-10.7 \%$ & $-3.9 \%$ \\
\hline Target Met & 0 & 0 & 0 & 0 & 0 & 0 \\
\hline
\end{tabular}

Figure 1: Comparison - Commencement, mid-season and end of season

\section{A Framework for Improving Perception of IT within the Organization}

While the overall results obtained in the September customer survey were somewhat expected the levels were of a surprise to the IT staff, the head coach, operations manager and the board. Given the perceived successful implementations of information technologies, it was anticipated that the results would have improved or at worst case remain the same. As such research was undertaken on how to improve the perception of the IT function and from the IT literature a sixstep model proposed by Peppard (2001) was identified. This model acts as a guide for studying the perception of IT. The six steps involve getting the basics right, enlisting key influencers, building credibility, seeking involvement early in projects, placing responsibility for IS with 
the organization (club) and cultivating and maintaining partnership.

Borkovich (2015) suggests education plays a key role in the acceptance of technology. At this stage it is important to impress upon the various coaching staff (business managers) the value created through the application of IT and the key role(s) IT plays in this process. The issue at hand in the organization appears to be the lack of understanding of the holistic process and benefits that IT systems are built upon. At this stage it is important for the understanding that the study focuses on the holistic education and its impact on perception of IT and not education on how IT systems work.

\section{Getting the basics right}

Peppard (2001) indicates the first stage comprises on focusing on the IS function itself, ensuring that it can, at least basically, deliver required IT services (Peppard, 2001). With this environment, while on a smaller scale, this involves basic IT functions such as network availability, support / help desk-like functions and reliability of applications.

Despite the improved use of project management, systems development tools and methodologies, the likelihood of failure in IT projects is still very high. The biannual Standish group surveys continue to show high rates of IT projects being cancelled before completion, delivered over budget, behind schedule and with less functionality and features than initially specified (Marchewka 2012). This is a disturbing statistic for IT departments eager to improve their perception of IT. Thus, it is important to get the basics of IT delivery and service to an acceptable level.

IT departments must make an extra effort to be proficient in project management, end user service and applications quality despite being an organization wide responsibility. Not achieved, it will be difficult for the basic expectation of IT meeting business requirements to be achieved.
Within the sporting organization guidelines for achieving the basics are in place:

1 Due to the size of this environment, a near $24 \times 7$ on call support is necessary during the competitive season to ensure network availability, problem fixes, etc. are addressed within minimal timeframes. All outages are reported weekly to the operations manager and head coach.

2 For project management, a suitable methodology needs to be incorporated and adhered to be all stakeholders - coaching staff, support staff and athletes.

3 Good and timely service is a performance objective for IT staff. Review of end user satisfaction is conducted at key point during the year and playing season, to address any short comings and is taken in to account at end of season and staffing reviews.

\section{Enlist key influencers}

Peppard (2001) identifies that there are key individuals in an organization who are pivotal to the success of the IT solution, and refers to these individuals as the socalled opinion leaders or key influencers.

For successful IT transformation, it is necessary to ensure that these influencers are on board as these individuals bring visibility to the IT project and add impetus to the implementation and acceptance process. However, care need to be taken as they can also decide the success or failure of an IT initiative. Key influencers may also exist within the organization (club) external to the coaching team, such as club and board members. These influencers may also have concerns regarding the applicability and use of the technology and changes to job roles due to system implementation. (Overby, 2005a).

Gonzales (2011) indicates there is a need for general managers to be involved in information systems due to the expenditure involved. Investment is wasted on automating inefficient processes when general managers are not involved 
due to the capability of IS to enable business initiatives such as business process re-engineering and total quality management, which may equally be applied to a sporting organization.

Key influencers are enlisted for the introduction of technologies and IT functions within this sporting organization. This is undertaken by ensuring that all projects are initiated and owned by the head coach. The head of the IT staff reports to the head coach and is in constant communicating with the other senior coaching and support staff. Weekly or fortnightly meetings are conducted to ensure that only items that are of high priority are being worked on.

\section{Build Credibility}

Credibility must be earned through achievements and positive results (Peppard, 2000) which needs to be kept in mind when establishing credibility of IT in a sporting organization.

It has been suggested by Overby (2005b) that IT staff should on a regular basis present the efforts and impacts of IT to the organization's board, their executive committee, other governing bodies and potentially to all stakeholders within the organization. This includes, not only project work, but also major maintenance and enhancement efforts, as well as successful results through the applications of technology.

To achieve success, a sense of trust and commitment, credibility must be developed between various participants to ensure a free exchange of beliefs and opinions. When credibility is lost it is difficult to regain as once a user perceives that someone or something lacks credibility, then they are likely to stop using the service or resource, hence providing no opportunity to regain credibility. Peppard (2001) considers education showing the value through the use of the technology and the key role it plays in this process is important.
A key component in building credibility is in the management of expectations and not over promise. Users have more faith in what the technology has to offer if IT delivers what has been promised. This is often a difficult concept to maintain for IT staff as users can be quite unrealistic in their demands and has to be managed.

Within the sporting organization there appears to be adequate communication to users indicating value of the technologies and IT. Relationship between IT staff and team management provides the ability for dialogue even though the organizational structures between IT staff and team coaching staff are less formal although the IT staff do have a contributing factor in the team decision making processes.

\section{Seek Involvement Early In the Implementation of Technologies}

Peppard (2001) indicates that the IT function should be seeking involvement of team stakeholders in the development of IS/IT projects and be involved willingly when opportunities are offered by stakeholders in the organization. From the perspective of project management, Marchewka (2012) suggests it is important to identify stakeholders as early as possible to enable the establishment of adequate communication channels at the commencement of any project, which additionally encourages the users to take responsibility with the project. The project's outcomes are more accurate when the stakeholders are responsible for the projects.

When users (coaching staff and athletes) and stakeholders are involved early in projects, there is less chance of missing important information or requirements about the desired way the system operates in their environment and how they use the technology. This additionally enables athletes and coaching staff to think about the testing process and diminishes potential frustrations following systems implementation.

In this organization, this process is working fairly well. The introduction of any 
technologies, whether they are IT process related or team related, has to be initiated and approved by the head coach and usually endorsed by the board. The project methodology ensures that the initiators of any technology related project(s) in the organization and the IT staff work closely, and more so where enforced signoff is required. The sign off process is often a point of frustration for the coaching staff as they feel that it delays the process but, once they recognize the value it adds to the outcome, they comply with the process.

\section{Place Responsibility For IS With The Organization}

Peppard (2001) has highlighted the importance of business managers taking responsibility for aspects of IT that traditionally may have been delegated to the IT function. As such, the senior team management in the sporting organization needs to take greater responsibility in the applications of technology.

There may be resentment in the taking on this responsibility as technology is foreign to them. However, they must realize they are making decisions that involve the using of technology rather than pure technical or technology decisions. This implies senior team management may need to be educated on how to make these decisions involving technology; however, they must take ownership for these decisions, which subsequently means taking responsibility for their component of the IT solution, including all new and existing technology and systems.

Success of the system requires commitment. Borkovich (2015) notes that it is important to have the values and benefits of the information technology accepted by those who will be using the technology. This in turn will change the perception to the acceptance of the introduced technology.

In this sporting organization all technologies and IT systems have a "business" owner - usually the head coach. Any changes made to existing or new systems have to be signed off by the head coach and endorsed by the board.

\section{Cultivate and Maintain Partnership}

There exists the potential of management becoming complacent and in turn not recognizing the contributions to the IT success. A project may not succeed simply because of the failures between IT staff and users interacting. Marchewka (2012) indicates quality communication and information exchange is a necessary key factor in the success in the development of an IS project.

The IT department's focus needs to be more to accentuate the relationships between IT and the users of the technology, rather than the being task oriented. Overby (2005b) indicates the development of relationships and/or partnerships with business units needs to be built which may necessitate IT departments to employ internal relationship managers to develop these relationships and hence set the foundation to improve perception.

Within the sporting organization, close relationships between IT staff and the senior coaching staff are visible at the higher management levels. The IT staff reports to the head coach and has a close relationship with other coaching staff. However, the level of the relationships is somewhat less with the team staff and players in the lower teams.

\section{Response to Negative Perception}

It appears that the sporting organization is following most of the recommendations given by Peppard (2001) in the six step framework. So why does this negative perception towards IT exist?

For sporting organizations to be competitive, it is important that they invest in addressing problems concerning their technology and IT functions. A negative perception of IT may not necessarily be a problem of the technology / IT staff as it could be related to stakeholders using the technology without a complete knowledge 
of how IT systems impact holistic process within the sporting organization.

Ward and Peppard (2002) believe Peppard's six-step process provides the possibility of improving the perception of IT through educating users. An education program could address the mindset blockages and thereby improving the perception of IT within the organization. Education plays a key role to influence team management in the process of value creation with the use(s) of IT and the key role that IT plays in this process (Peppard, 2001).

Other literature supports the notion of education and training being used as a means to improve the views users have of the use of IT. Olfman et al. (2014) believe education and training is a strategic necessity to stay competitive and deliver results. The literature shows that traditionally IT training has been to impart skills required in the use of the particular systems to users. Olfman et al. (2014) indicates that programs to develop IT skills are typically built to illustrate the semantics of the system's functions. Training needs to be focused on 'what' the system can do and not 'why' it does what it does.

There appears to be little focus on how the system covers a holistic business process and adds value to the organization. By neglecting this aspect of the value of a system, there is little business ownership. In their study on organizational learning strategies, Olfman et al. (2014) suggest that there is little business focus in terms of application of IT skills to business process and understanding what these skills and systems will do for the individual and the organization. They emphasize that the capability to focus on the larger business picture requires training in IT skills be considered integral to the organizational strategies.

In an era where sporting organizations are increasingly dependent on IT for value and gaining competitive edges, it seems remarkable that there is limited focus on this topic within sporting organizations. IT training must focus on the organizational needs not just how to use the system. End users must understand the holistic process, and how IT assists them in achieving their individual and team goals.

Earlier Ewusi-Mensah and Przasnyski (1991) indicated that $30 \%$ of the executives who responded to their survey on information systems abandonment indicated end users experiencing uncertainty in relation to an information system's impact on their job. This potentially lead to negative perceptions of what IT has to offer and eventuated in abandonment of the technology which may have actually been of benefit to the organization. Zaremohzzabieh et al (2015) noted, with a perceived usefulness of technology, there was a greater correlation to the intention to adopt and use the technology.

The approaches to training and methods employed have predominantly focused on ensuring that a trainee acquires the necessary skill sets to use an IT tool and in a specific domain. However, with the advent and increasing use of technologies and IT solutions, this narrow view of training will prove to be inadequate in preparing sporting organizations, teams and athletes of the future. It is important to incorporate a conceptual level of IT training, which refers to viewing the tool in the context of the entire system and the organization and the application of the system.

\section{Conclusion and Future Research}

The value of IT in sporting organizations is undervalued and the IT staff in such organizations stumble to facilitate the organization's demands for return on IT value. Sporting organizations that fail to take on the potential benefits in the uses and applications of IT will miss opportunities for innovation and in all likelihood spend IT expenditure inefficiently. Many have taken up the challenge of recommending potential solutions to improve the uses and value of IT. This needs to be done in a manner allowing the organization to have the potential to become innovators and 
through the applications of technology, gain competitive edges.

The challenge for a sporting organization's IT staff is to enable all stake holders within the organization to see and accept the value and benefits in IT, and subsequently improving the perception of IT. It appears, through this work, that this may be possible with the improvement of educational methods and training for end users. This may achieved through implementing complete training in the technology along with the introduction of the IT system.

This study's significance is in the examination of how a sporting organization may increase the acceptance and effectiveness of relevant technologies to create advantage. By formulating a strategic learning module for end users, it can assist the organization to stay competitive, provide a better training and match preparation environment for the organization's teams and athletes, achieve better results and potentially deliver an attractive environment to attract other athletes to the club/sporting organization. By understanding the value of IT, the sporting organization may be able to service their coaching and support staff and athletes more effectively. The findings may be applied to other organizations facing similar negative perceptions of IT or potentially where the IT department is viewed poorly.

\section{References}

1. Abdillah, L.A., (2014). Managing information and knowledge sharing cultures in higher education institutions. arXiv preprint arXiv:1402.4748. [Online] [ Retrieved December 1, 2016] https://arxiv.org/ftp/arxiv/papers/1402/ 1402.4748.pdf

2. Avison, D.E., Cuthbertson, C.H., Powel, P., (1999), "The Paradox of Information Systems:Strategic Value \& Low Status', Journal of Strategic Information Systems, 8(4), 419-445

3. Beheshti, H.M, (2004), 'The Impact of IT on SMEs in the United States', Information
Management \& Computer Security, 12(4), 318-327

4. Bhardwaj, D., (2007), 'Relationship Marketing in Context to the IT Industry', VISION -The Journal of Business Perspective, 11(2), 57-66

5. Borkovich, D.J., Breese-Vitelli, J and Skovira, R.J., (2015). 'New Technology Adoption: Embracing Cultural Influences', Issues in Information Systems, 16(3). [Online] [ Retrieved December 1, 2016] http://www.iacis.org/iis/2015/3_iis_2015 _138-147.pdf

6. Cormack, S, Cater-Steel, A, Horn Nord, J and Nord, D.G. (2001), 'Resolving the Troubled IT-Business Relationship from a Cultural Perspective', Proceedings of the 12th ACIS Conference, Coffs Harbour, Australia

7. Daft, R.L. (1997), Management, 4th ed., Dryden Press, Fort Worth, TX

8. Doherty, N.F. (2014), 'The role of sociotechnical principles in leveraging meaningful benefits from IT investments.' Applied ergonomics,45(2), 181-187. [Online] [Retrieved December 1, 2016] http://www.sciencedirect.com/science/art icle/pii/S0003687012001895

9. Duhan, S., Levy, M. and Powell, P. (2001) 'Information systems strategies in knowledged-based SMEs: the role of core competencies', European Journal of Information Systems, 10(1), 25-40.

10.Erlandson, D.A, (1993), Doing a Naturalistic Inquiry: A Guide to Methods, Newbury Park, CA.

11.Ewusi-Mensah, K. and Przasnyski, Z. H. (1991), 'On Information Systems Project Abandonment: An exploratory Study of Organisational Practices', MIS Quarterly, 15(1), 67-85

12. Gonzales, M. (2011), 'Success factors for business intelligence and data warehousing maturity'. Business Intelligence Journal, 16(1), 22-29

13.Horn Nord, J., Nord, D.G., Cormack, S., and Cater-Steel, A (2007), 'An Investigation of the Effect of Information Technology (IT) 
Culture on the Relationship between IT and Business', International Journal of Management and Enterprise Development, 4(3), 265-292

14.Huang, C.D. and Qing $\mathrm{Hu}, \mathrm{Q}$. (2007), 'Achieving IT-Business Strategic Alignment via Enterprise-Wide Implementation of Balanced Scorecards', Information Systems Management, 24, 173-184

15.Lunney, A., Cunningham, N.R., and Eastin, M. (2016), 'Wearable fitness technology: A structural investigation into acceptance and perceived fitness outcomes' Computers in Human Behaviour, 65, 114-120 [ Online] [ Retrieved Dec 1, 2016]

http://www.sciencedirect.com.ezproxy.lib. uts.edu.au/science/article/pii/S07475632 16305714

16. Maklan, S., Peppard, J. and Klaus, P. (2015), 'Show me the money: improving our understanding of how organizations generate return from technology-led marketing change.' European Journal of Marketing, 49(3/4), 561-595.

17. Marchewka, J.T. (2012) Information Technology Project Management, 4th ed., John Wiley \& Sons, Hoboken, NJ

18. McCraken, G., (1988), The Long Interview, Newbury Park, CA, 1988

19. Milton, C.R., Entrekin, L., \& Stenning, B.R. (1984), Organizational Behavior in Australia, Prentice-Hall, Sydney

20.Nguyen, T.H., Newby, M. and Macaulay, M.J. (2015). Information technology adoption in small business: Confirmation of a proposed framework. Journal of Small Business Management,53(1), 207-227.

21. Olfman, L., Bostrom, R.P. and Sein, M.K. (2014). 'Developing training strategies with an HCI perspective'. Human-Computer Interaction and Management Information Systems: Applications. Advances in Management Information Systems, 258.

22. Overby, S. (2005a), 'FALSE Perceptions', CIO Magazine, 18(16), 65-70.

23. Overby, S. (2005b), 'Turning IT Doubters Into True Believers', CIO
Magazine, [Online] [ Retrieved August 23, 2013]

http://www.cio.com/article/print/6740

24.Park, J., Lee, J., Lee, H. and Truex, D. (2012). Exploring the impact of communication effectiveness on service quality, trust and relationship commitment in IT services. International Journal of Information Management, 32(5), 459-468. 「Online† [Retrieved November 28, 2016$]$ http://www.sciencedirect.com/science/art icle/pii/S0268401212000266

25. Paroutis, S., Bennett, M. and Heracleous, L. (2014). 'A strategic view on smart city technology: The case of IBM Smarter Cities during a recession'. Technological Forecasting and Social Change, 89, 262-272.

26. Patton, M. (1990) Qualitative Evaluation and Research Methods (2nd ed.). Thousand Oaks, CA: Sage

27. Peppard, J.W. (2001), 'Bridging the gap between the IS function \& the rest of the business: Plotting a route', Information Systems Journal, 11, 249-270.

28. Ramakrishna, H.V. and Lin, X. (1999), 'Perception of the Role of Information Technology Function in Organisations: Toward the Development of a Measure', ACM SIGCPR Computer Personnel, 20(4), 3954.

29. Reich, B.H. and Benbasat, I., (2013), 10 Measuring the Information SystemsBusiness Strategy Relationship. Strategic Information Management, 265.

30.Rieh, S.Y., Morris, M.R., Metzger, M.J., Francke, H. and Jeon, G.Y. (2014), Credibility perceptions of content contributors and consumers in social media. Proceedings of the American Society for Information Science and Technology, 51(1), 1-4. [Online] [Retrieved November 28, $2016]$

http://onlinelibrary.wiley.com/doi/10.100 2/meet.2014.14505101022/full

31.Štok, Z., Markič, M., Bertoncelj, A., \& Meško, M. (2010), Elements of organizational culture leading to business excellence. Zb.rad.Ekon.fak.Rij., 28(2), 303318. 
32.Sun, P. (2010), 'Five knowledge organizational themes'. Journal of Knowledge Management, 14(4), 507-523

33.Ward, J. \& Peppard, J. (2002) Strategic Planning for Information Systems, 3rd ed., John Wiley \& Sons Ltd, Chichester

34.Yin, R.K. (2003) Case Study Research: Design and Methods, Sage Publications, Thousand Oaks, CA, 3rd edn.
35.Zaremohzzabieh, Z., Bahaman abu Samah, B., Muhammad. M., Omar, S.Z., Bolong, J., Hassan, M.S., Shaffril, H.A.M. (2015) 'A test of the technology acceptance model for understanding the ICT adoption behavior of rural young entrepreneurs' International Journal of Business and Management, 10 (2), 158-169 